\title{
The Improvement of Higher Education Quality and Talent-Nurturing with Scientific Students' Association (SSA) Commitment
}

\section{Roland Bérces}

Department of Management and Corporate Economics, Budapest University of Technology and Economics (BME)

Magyar tudósok körútja 2, Bld. Q/A313, H-1117 Budapest, Hungary

Email: rberces@mvt.bme.hu

Abstract: In the article, I interpreted talent-nurturing as a key process of managing the quality of higher education and analyzed the Scientific Students' Association as a tool for successfully nurturing talents. By using analytical statistical methods, I showed which reasons motivate our students to join the Scientific Students' Association, and if those who participate in this particular form of university talent-nurturing share any common features or characteristics. Based on the results, I proposed quality improvement suggestions, which can increase the number of students that join formal talent-nurturing programs, thus, becoming more valuable for all higher education institutions.

Keywords: higher education; quality management; talent-nurturing; student motivation; statistical analysis

\section{Introduction and Theoretical Background}

Education quality improvement has long been a research topic at the Budapest University of Technology and Economics (BME). Our department has long been the flagship of our university, both in regard to offering courses on quality management and conducting research in the field. We have been observing student expectations/opinions about the courses offered by our department for a long time, and we are also engaged in the issue of measuring and evaluating. [10] [11] We constantly broaden our experience and are on the lookout for new methods in order to continuously develop the education quality of our department and our faculty. However, until now we have not analyzed how the Scientific Students' Association (SSA) system works at our faculty, even though this system is an important quality factor in the operation of our faculty. Besides the fact that the appropriate improvement of the SSA system - regarded here as a knowledge management system - can contribute to the organizational performance [6] of the 
Faculty of Economics and Social Sciences (FESS) at BME, we feel that the SSA system is perceived as an important tool and opportunity by our students to develop new and interesting research areas beyond their studies and to expand their professional experience. This implies that the SSA - besides many other tools - is also a quality-improving tool that can raise the satisfaction of our students and spread the good reputation of our university; thus, the analysis of student motivation and how the system works suits the quality development practice of our university. [5]

It has always been important for higher education institutions to admit a suitable number of students. In recent years, a decrease in financial sources caused by the economic crisis and the dropping number of students due to the unfavorable demographic trends have made it more important to admit a number of students close to the maximum capacity and to recognize, support and keep the more talented and skilled students from a smaller pool. The reason for this, on one hand, is that this is the best way in the framework of the multi-level higher education to encourage BSc graduates to carry on their studies at the Master's level. On the other hand, the need for taking in new members for the university teaching staff and the natural changes in the aging teaching staff both require that some of the talented students get a Ph.D. and start an academic professor/researcher career.

Besides the application of different education quality management systems for reaching long-term strategic goals, the issue of nurturing talents has risen again as an element that determines and is thus fundamentally related to the quality of education.

However, the SSA is primarily a special way of scientific education at our university, but - besides improving the level of education at the faculty - is also could be a tool of this talent-nurturing, and it is already quite well-known among our students; however, we still feel the need to make it more popular and, thereby, include as many students as possible in our work.

\subsection{Talent-Nurturing as a Key Process of Quality Management}

The issue of quality management in the higher education is only one interpretation frame of the educational processes, beside many others. Some higher educational researchers say it is especially the outcome of "managerialism" at the university. In my opinion the quality management in the higher education is one of the most important issues, a lot more than just institutional management. In my article, I interpret talent-nurturing as one key factor in the quality of higher education. From Garvin's five approaches to quality, I regard the production and process approaches of higher education (content of programs and educational plans, academic work of professors, etc.) as equally important as the user-based interpretation of quality - according to which, the quality of higher education means compliance to the user demands, where users are the students, the firms 
that will apply them and the state that partly or completely finances their education - and the value-based approach (according to which, the institute offers and the student receives a certain quality for a certain price and effort. [2] It suits this approach to consider talent-nurturing as an element of quality improvement.

Concerning talent-nurturing, I believe that the principle of quality, as a "zero defect" is not applicable. This approach describes quality as a constantly faultless result. It is principally, organizations that use this approach, where the product, service or result is preceded by pre-determined, fixed standards. The 'zero faults' are mostly common in mass production, where it is not an issue to provide and measure detailed product specifications, standardized features and product compliance. In higher education, however, this point of view would be problematic even in its basics, as the students, unlike the products, are not the same; it would be difficult to determine what is considered faultless. This is even truer if we consider talent-nurturing students who possess different talents and different learning methods in different fields, and the selection and mentoring of these students. [17] When considering education supplementary materials or talent-nurturing, such as the SSA as a process, the situation is different as the faultlessness can be determined more effectively based on lecture notes, lecture manuals or when conducting a conference. If we regard higher education as a standard process that always delivers the same result [16], with the provider considering the price and quantity, and the consumer (student) considering the type (qualification) and quality (party the talent-nurturing) as a primary factor, we can point out that higher education can also be characterized by the global spreading of the so-called 'McDonaldization' that is the standardization mentioned above. [14] The standardization of the service provision by the professors is only sometimes disturbed by students who do not fit into the system. Conflicts in the service interactions can be caused both by the irregular conduct of the provider and the irregular user attitudes or behavior. We refer to this as the socalled 'jaycustomer misbehavior'. [9] It is unclear whether the behaviors that interfere with the system can improve the service quality or just hinder the process, which is improved by McDonaldization. If the SSA system aimed to recognize 'non-fitting' talented students, this would be regarded as a jaycustomer misbehavior. [7] I suggest that the talented and hard-working students often feel unfit to the system in the current days, and their performance is frequently cut back by the speed of education that is adjusted to the skills of the average student. The SSA system can be a good opportunity for these students to suit higher expectations by developing their own professional knowledge and, with the help of feedback, to contribute to the improvement of the SSA system and to the quality of faculty services.

The correct interpretation of talent-nurturing processes is further aggravated by the issue that the student is, the consumer, the subject and the 'final product' of the educational services. [3] 


\subsection{The Contributions to the SSA as a Tool for Talent- Nurturing}

The concept of talent has been discussed in many past works. Based on several approaches and much research, we have to begin with the statement that talent can be characterized by: creativity, motivation, performance and above average skills. High-level abstract thinking, advanced mother language skills, good memory and effective information processing strategies are all examples of over-average general skills. Their role, of course, differs in each special field of talent. Creativity is composed of several elements: originality, flexibility, fluency, problem-sensitivity, etc. This component is also significant concerning the functions of the talent, as a talented person can be characterized by finding new solutions when encountering problems: a process that is not feasible without creative abilities. Motivation serves as a basis for being committed to the task, and it is a tool for being curious, hard-working, ambitious, interested and persistent. There is no performance without motivation either, which would be a necessary condition for showing and expanding talent. Beyond the abilities, hard work, persistence, willpower, or, in one word, motivation is needed for a learning result. Without hard work and the readiness to perform, the talent would not develop. [12] In the field of nurturing and managing the talents, higher education aims to firmly attend to talented people. Young people getting into higher education have a more significant potential in terms of certain abilities than in other aspects. They can achieve their goals by improving their strength and through reassurance, as well as by compensating for weaknesses. A 'creative atmosphere' is considered most favorable for a talented youngster to enrich his/her knowledge and intellectual capital as it provides an auto-dynamic freedom and autonomy based on mutual trust for his/her activity and performance. The SSA system of BME as a special way of scientific education at our university - provides an excellent field for this process to come true, as it is considered a self-training method that ensures opportunities to deepen the compulsory knowledge related to the learning material, to gain beyond-the-curriculum knowledge and to carry out and get publicity for student research. By running these SSAs, the BME completely complies with the regulations of the higher education law, which points out that it is tasked to search for and recognize highly talented and motivated students or students with handicapped or multiple-handicapped backgrounds and to promote professional, academic, artistic or sport activities. [13] SSAs have the principal task of identifying the talent. For this, it is necessary to realize that an excellent performance in higher education is composed of inner cognitive and motivational factors (such as individual talent potentials) and a socially stimulating learning environment. [8] The formation of excellence can be stimulated with the following factors: Creative learning environment, well-balanced group dynamics, good teacher-student relationships, inclusion of talented students in teaching [15] [19] The process above can be noticeably pointed out in the 'Munich dynamic talent model' by Ziegler and Perleth, as well. [1] 
After the talent has been identified, students need constant support and help while participating in the program. That is why the mentor system has been formed in higher education. The tutor, as an instructor, is tasked with helping the student and participating in the process of talent-nurturing. Mentoring means attending to advisory tasks, with participation, for a longer period of time. Mentoring may also mean that the mentor follows that talent in his/her occupation. In both cases it is important to serve as an example and to create an interactive relationship in which the talent gets confirmation and positive feedback for his/her activity and motivation and support to fix his/her weaknesses. Communication is the basis of this interactive relationship, and its significant role can also be measured in how the life of the talent goes. [4] If the properly identified talented student can form and maintain an excellent student-instructor relationship, the student will most likely be motivated to participate in professional/scientific tasks above the level of basic expectations, like in SSA conferences. It is difficult to analyze if the identification of the talent and the early mentoring work well, but if they both do, then the result of this will be evident in the formal SSA conference in terms of the papers and the participating students. Therefore, we aimed our analyses at SSA conferences and those who participated or were willing to participate (students in early phases of mentoring) in them.

\subsection{Talent-Nurturing and SSA, at the Faculty of Economics and Social Sciences of the BME}

An important event of the FESS at the BME is the annually organized SSA conference. With our events, we have been aiming to provide our students with a forum where they have the opportunity to present their first steps towards an academic contribution. We expect from the submitted papers that the authors indulge in their chosen topics beyond the official curriculum. This feature shall be present in the chosen methodology and in the topic selection; in the latter, the students provide a deeper analysis of issues that were barely touched upon during teaching, or they examine topics that were not covered in class activities. The instructors also assist the authors of SSA papers and, in several cases; a thesis will be a later result of this cooperation. Table 1 contains the statistical data of the SSA conferences of the FESS from the last seven years. The data reflects a rippling tendency both in regards to the number of papers and authors. The downturn that has been going on since the peak in 2011 can be explained by the fact that we have placed a bigger emphasis on quality, we have taken our above goal very seriously and have encouraged the authors to present their own contribution to the topics (order principle, analysis, evaluation, etc.), thus, selecting papers for presentation more strictly. It is a constantly present problem that Bachelor's students are considered in the same sections as Master's students. (Students now participate in equal numbers from both educational levels). 
Table 1

The statistical data of the SSA conferences at FESS

\begin{tabular}{|l|c|c|c|c|c|c|c|}
\cline { 2 - 8 } \multicolumn{1}{c|}{} & $\mathbf{2 0 0 7}$ & $\mathbf{2 0 0 8}$ & $\mathbf{2 0 0 9}$ & $\mathbf{2 0 1 0}$ & $\mathbf{2 0 1 1}$ & $\mathbf{2 0 1 2}$ & $\mathbf{2 0 1 3}$ \\
\hline No. of papers & 110 & 121 & 132 & 137 & 145 & 131 & 118 \\
\hline No. of authors & 128 & 128 & 145 & 149 & 157 & 137 & 136 \\
\hline Authors outside FESS & 25 & 24 & 26 & 29 & 26 & 20 & 40 \\
\hline Sections (Ph.D.) & $16(1)$ & $14(3)$ & $18(3)$ & $19(1)$ & $18(1)$ & $18(1)$ & $15(1)$ \\
\hline No. of paper advisors & 80 & 83 & 72 & 93 & 91 & 75 & 66 \\
\hline No. of 1 $\mathbf{1}^{\text {st }}$ places & 16 & 20 & 23 & 26 & 25 & 21 & 18 \\
\hline No. of 2 2 $^{\text {nd }}$ places & 15 & 17 & 19 & 22 & 22 & 21 & 16 \\
\hline No. of 3 3 $^{\text {rdaces }}$ & 18 & 22 & 13 & 14 & 22 & 21 & 13 \\
\hline No. of merits & 40 & 41 & 11 & 12 & 18 & 13 & 21 \\
\hline
\end{tabular}

Up to now, we have pursued the practice of setting up the sections in a topic-based manner, which enabled students working in similar topics to comment on the papers of others while also getting a great deal of useful feedback for their own work. Principally, we consider the discussions developing in sections as important, as this is the first time for many participants to step up in front of a large audience and explain or even defend what they discussed in their paper. Additionally, the SSA conference at the FESS has several special features: ca. $15 \%$ of the participating students are from the Engineering faculties of the BME and related to the conference and Ph.D. students and students from abroad (the latter for the first time in 2013) are granted the opportunity to present their results. In the $31^{\text {st }}$ National SSA (NSSA) conference in 2013, the FESS was represented with 41 papers. Our students achieved better results than in the conference of 2011 (and in the years before that): in 2013, they achieved seventeen places and eight special prizes in six sections. Finally, we believe that the FESS activity of our faculty can be considered successful because of these results.

In the rest of my article, I will use a survey conducted among the students of the FESS at the BME to find out how the SSA conferences, which boast a long tradition and many results, can be made more popular for students and how we could attract more students to contribute. For this, it is necessary to assess what factors motivate students to prepare an SSA paper, what factors they rely on when they decide to participate in the university or national SSA conferences several times, and also if there are any common characteristics that are shared by students participating in SSA as a talent-nurturing program (and, thus, undertaking extra work). I suppose that such characteristics exist and that the desire to stand out from the standard mass education processes, to collaborate with a mentor and the joy of conducting research together all form a part of the students' motivation. 


\section{The Empirical Analysis}

\subsection{Methods}

Although the SSA activity of the university and the faculty is successful, through the continuous improvement principle, which was included in the faculty's quality policy, I deemed it necessary to conduct a deeper analysis in order to obtain answers for the following questions:

Q1: Which students participate in the SSA? Is there any connecting point in the attitude or circumstance of the students applying for the SSA and is there a common feature that is generally a characteristic of the students joining the SSA?

Q2: Why do our students plan to participate in the SSA?

Q3: Are there any further factors that motivate those for participation who only intend to join or those who have already prepared an SSA paper (at least) once?

Q4: Are the students who have already prepared an SSA paper willing to prepare it once again? If so, have their reasons changed?

Based on the questions above, I have formulated the following hypotheses:

H1: We will find a common feature that is shared by a large majority of our students who participate in the SSA.

H2: Our students start an SSA paper because of the joy of making a professional contribution and the opportunity for self-development

H3: A difference in the motivational factors can be shown between the group of students who are only planning to participate and the group that have already participated and therefore know the system internally.

H4: The students' motivation will change after the first SSA and will undertake the preparation of the second SSA for reasons that are different from the ones for the first SSA.

By answering the questions above, I expect to be able to prepare proposals that can not only reduce fluctuations in the number of students applying for the SSA each year, but can also increase the number of students accepted into the SSA. The answers provided for each question can help boost the effectiveness of the 'identification' phase of talent-nurturing and assist the faculty in choosing and applying the right marketing and motivational tools. They may make it easier for the faculty not only to find talented students, but also to motivate the already found (those who have already submitted an SSA paper) ones to carry on their work. I believe that, this way, we will make a contribution not only to the increase of student (customer) satisfaction in our faculty, but also to finding, aiding and mentoring students (at the highest level and as early as possible) who are applying 
for an MSc or Ph.D. or concerning the most talented ones, for an instructor/researcher career.

I have chosen the questionnaire, non-random sampling and quota type of interview [18] in order to obtain answers to my research questions. As both the ratio of students admitted to the faculty and that of participants in an SSA conference was around fifty-fifty percent, I used this as a control category. Within this, I used the discretionary sampling technique: I asked Bachelor's and Master's degree students, and the participants of our earlier SSA conferences, to fill out the anonymous questionnaire. Concerning questions 10 and 15 of the questionnaire, I aimed to discover the motivations of students associated with SSA, while, in the other questions, I tried to discover certain common characteristic features of the students. Taking into consideration the incoming answers and the determined quotas, I regarded the first 200 Bachelor and 200 Master answers, with $60 \mathrm{BSc}$ and 60 MSc SSA participants. The questions for the students and the types of possible answers are contained in Table 2.

Table 2

The questionnaire for the students

\begin{tabular}{|c|c|c|}
\hline & Question & $\begin{array}{l}\text { Type of } \\
\text { answer }\end{array}$ \\
\hline 1. Are you a member of a & udent college? & Yes/No \\
\hline 2. Are you a member of a & fficial sports club? & Yes/No \\
\hline 3. Are you committed to & untary social work in your free time? & Yes/No \\
\hline 4. Do you read academic & oks or journals in your free time? & Yes/No \\
\hline 5. Are you an active men & r of a university or academic library? & Yes/No \\
\hline 6. Do you receive a regul & study grant? (in the current semester) & Yes/No \\
\hline $\begin{array}{l}\text { 7. Did you participate in } \\
\text { secondary school years? }\end{array}$ & NCSSS in any of your subjects during your & Yes/No \\
\hline $\begin{array}{l}\text { 8. Have you ever particip } \\
\text { competition? (during you }\end{array}$ & $\begin{array}{l}\text { d in a university study or case study } \\
\text { ears at university up to now) }\end{array}$ & Yes/No \\
\hline $\begin{array}{l}\text { 9. Have you participated } \\
\text { years at university up to } 1\end{array}$ & $\begin{array}{l}\text { a university education abroad? (during your } \\
\mathrm{v} \text {, for a period longer than two months) }\end{array}$ & Yes/No \\
\hline $\begin{array}{l}\text { 10. Have you participate } \\
\text { faculty? (during your yea }\end{array}$ & $\begin{array}{l}\mathrm{n} \text { an SSA conference organized at a BME } \\
\text { at university up to now) }\end{array}$ & Yes/No \\
\hline & 1. presentation of an academic work condu & arlier \\
\hline 11. What was the reason & 2. getting to know an interesting problem/f & science \\
\hline $\begin{array}{l}\text { for your conference } \\
\text { participation? (you may }\end{array}$ & 3. development of presentation skills & \\
\hline select more than one & 4. preparation for writing a thesis or degree & ment \\
\hline answer - please answer & 5. earning extra points for continuing educa & \\
\hline $\begin{array}{l}\text { the question only if you } \\
\text { replied with a 'yes' for }\end{array}$ & $\begin{array}{l}\text { 6. the opportunity for professional success a } \\
\text { acknowledgement }\end{array}$ & \\
\hline & 7. earning extra points for a study grant & \\
\hline & 8. the hope for a financial reward that accon & es the prizes \\
\hline
\end{tabular}




\begin{tabular}{|c|c|c|c|}
\hline & \multicolumn{3}{|l|}{ 9. research experience } \\
\hline & \multicolumn{3}{|l|}{ 10. other } \\
\hline \multicolumn{3}{|c|}{$\begin{array}{l}\text { 12. Are you planning to participate in a university study or case study } \\
\text { competition in the remaining years of your university studies? }\end{array}$} & Yes/No \\
\hline \multicolumn{3}{|c|}{ 13. Are you planning to participate in a university education abroad? } & Yes/No \\
\hline \multicolumn{3}{|c|}{$\begin{array}{l}\text { 14. Are you planning to participate in an SSA conference organized at a } \\
\text { BME faculty? }\end{array}$} & Yes/No \\
\hline \multicolumn{3}{|c|}{ 15. Are you considering an academic career in the future? } & Yes/No \\
\hline \multirow{10}{*}{$\begin{array}{l}\text { 16. Why are you } \\
\text { planning to participate in } \\
\text { an SSA conference in the } \\
\text { future? (you may select } \\
\text { more than one answer - } \\
\text { please answer the } \\
\text { question only if you } \\
\text { replied with a 'yes' to } \\
\text { question 14) }\end{array}$} & \multicolumn{3}{|c|}{ 1. presentation of an academic work conducted earlier } \\
\hline & \multicolumn{3}{|c|}{ 2. getting to know an interesting problem/field of science } \\
\hline & \multicolumn{3}{|c|}{ 3. development of presentation skills } \\
\hline & \multicolumn{3}{|c|}{ 4. preparation for writing a thesis or degree assignment } \\
\hline & \multicolumn{3}{|c|}{ 5. earning extra points for continuing education } \\
\hline & \multicolumn{3}{|c|}{$\begin{array}{l}\text { 6. the opportunity for professional success and } \\
\text { acknowledgement }\end{array}$} \\
\hline & \multicolumn{3}{|c|}{ 7. earning extra points for a study grant } \\
\hline & \multicolumn{3}{|c|}{ 8. the hope for a financial reward that accompanies the prizes } \\
\hline & \multicolumn{3}{|l|}{ 9. research experience } \\
\hline & \multicolumn{3}{|l|}{ 10. other } \\
\hline \multicolumn{3}{|c|}{ 17. What is your current level of education? } & $\mathrm{BSc} / \mathrm{MSc}$ \\
\hline \multicolumn{2}{|c|}{ 18. How do you evaluate your financial situation? } & $\begin{array}{l}\text { below average/ave } \\
\text { average }\end{array}$ & age/above \\
\hline \multicolumn{3}{|c|}{ 19. Do you live in a student dormitory? } & Yes/No \\
\hline
\end{tabular}

\subsection{Evaluation of the Questionnaire}

\subsubsection{Analysis of Motivational Factors}

First, I investigated the answers given to questions 11 and 16 (the ones related to the motivational factors of SSA). A student could select more than one answer in these questions; thus, we can analyze the occurrence ratio of each reason (and their weight) as compared with all the possible answers. Figure 1 shows the occurrence ratio of answers 1-9, which could be selected for questions 11 and 16, compared to all selected answers. ${ }^{1}$ One hundred and twenty students from the sample of 400 already finished an $\mathrm{SSA}^{2}$, and 178 students were planning to do an SSA in the future. Thus, 298 students picked the choice of already having been or are planning to be involved in the SSA.

$1 \quad$ For questions 11 and 16, I did not take into consideration answer 10 (categorised as 'other') in the graph because only a few responses were received in this 'other' category.

2 For our students at the BME to participate in the SSA work means that they have to write and submit a cca. 20-30 page paper at the annual BME SSA conference. 
This is an impressive result, even if I consider that the 249 participants of the SSA conferences of 2012 and 2013 were originally sent the questionnaire as well, and they replied with a response rate of $48 \%$. These 298 individuals are in fact 230 students as there were 68 students who have already participated in SSA and are planning to be involved in it again in the future. I will assess these 230 students somehow involved in SSA and their answers in our oncoming analyses. The high answer rates shown in Table 3 can also be explained by the fact that I asked our students studying quality management who were currently learning about different methods of measuring customer satisfaction and about the importance of feedback analysis to fill out the questionnaires; therefore, the topic and their studies both motivated them to return the questionnaires.

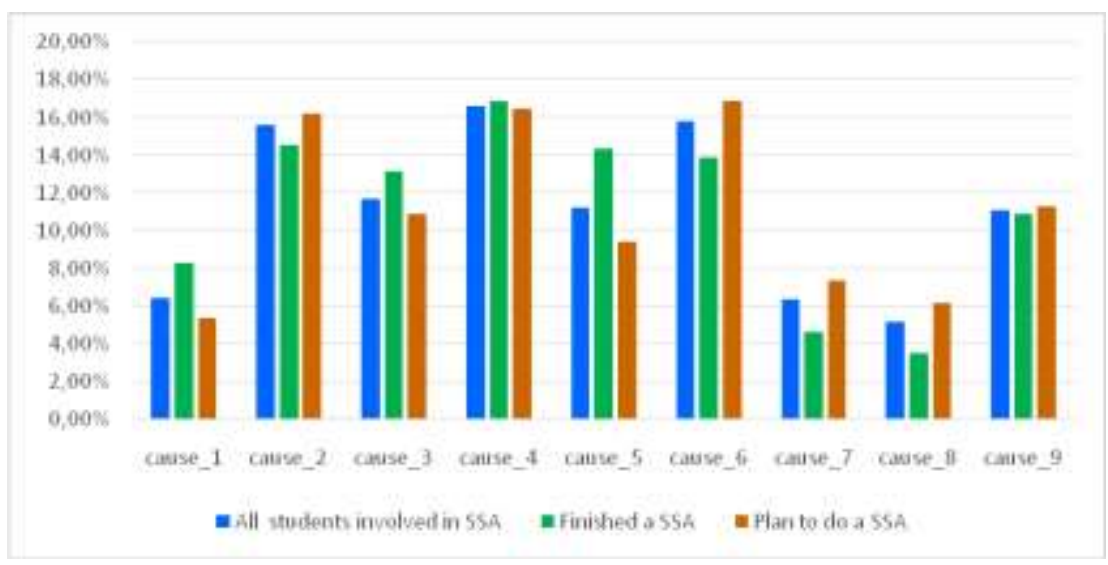

Figure 1

Reasons for preparing an SSA paper - occurrence ratio of each answer compared to all

When analyzing the answers with descriptive statistics, I can point out that the students selected the following three reasons for SSA involvement, both in the analyzed grouping and overall: getting to know an interesting problem/field of science, preparation for writing a thesis or degree assignment and the opportunity for professional success and acknowledgement. The development of presentation skills, earning extra points for continuing education (Master's degree studies and a Ph.D.) and research experience were considered to be of average importance. The students regarded the presentation of an academic work conducted earlier, earning extra points for a study grant (faculty, professional, university and international grants) and the hope for the financial contribution that accompanies the prizes as the least important factors. The reasons of least important are feasible. It is only a small number of students who already have previous academic work, and an SSA paper is the first, more serious assignment that most of them encounter outside their lectures. Our personal experience also supports the argument that students are not aware of the different types of student grants, the conditions of getting such grants and how to apply for them. Besides, the SSA paper is not counted as an extra point in every student grant; therefore, it is clear that this aspect motivates 
them less. It is a good sign, however, that the thirst for professional knowledge and gaining professional knowledge are among the most important motivational factors, accompanied by the practical reason that a high-quality SSA paper can be the basis of a thesis or degree assignment in a couple of semesters.

By comparing the results with a homogeneity test ( $\chi 2$-test), I find that the reasons given by students who already participated in the SSA and those who intend to significantly differ in several aspects $(\chi 2=58.05 ; \mathrm{df}=8 ; p=0)$.

Besides, as there were many (68) students among the ones who already submitted an SSA paper and were planning to participate in the future as well (120 students), it is worth analyzing the reasons of each of these groups separately as well and comparing them with the reasons of students who are not yet involved in SSA but are planning to be so in the future (Figure 2).

I divided the students who indicated their past involvement or plans about future involvement into the following groups, and then carried out the respective homogeneity tests $(\chi 2$-test):

Group A: Students who already participated in SSA: 120 students

Group B: $\quad$ Students who already participated in SSA and are planning to do so again: 68 students

Group C: $\quad$ Students who have not yet participated in SSA but are planning to do so: 110 students

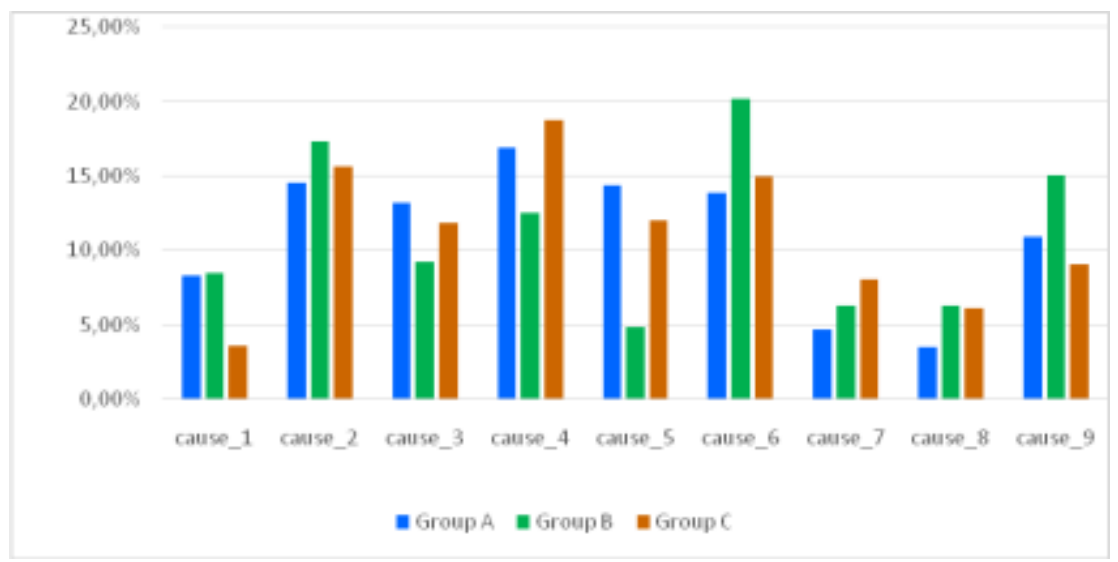

Figure 2

The reasons for preparing an SSA paper - among the ones who already participated and those are planning to do so - the occurrence rate of each answer is compared to all the answers

The $\chi^{2}$ test results (Group A-B: $\chi^{2}=45.08$; Group A-C: $\chi^{2}=39.85$; Group B-C: $\chi^{2}$ $=104.76(\mathrm{df}=0, \mathrm{p}=0))$ confirms the presupposition suggested by the chart here as well. 
It is evident that there are significant differences among the reasons of each group. On one hand, the values are above average for students participating in their second SSA for different reasons compared to their first SSA (group A vs. group B); on the other hand, those who are planning to do an SSA have very different reasons from those who have already participated but are not planning to do so again (group C vs. group A) and also from the ones who have already participated and are planning to do so again (group C vs. group B). In the following points, without presenting the results in detailed numbers, we aim to introduce the most important conclusions that served as a basis for setting up our further and more complex aspects of analysis:

1) Those who have already prepared an SSA paper (group A), not considering if they want to do it again or not, selected preparation for writing a thesis or degree assignment as the most important reason. Besides this, they picked the following reasons: getting to know an interesting problem/field of science, professional success and earning extra points for continuing education in high numbers. These students are more motivated than the average university student is, as they have applied for the SSA conference, which requires a lot of extra work; however, it can be supposed that they regarded the completion of their SSA paper as a pre-task for writing their thesis, and they had lost their further motivation after preparing a successful SSA paper.

2) Those who have prepared an SSA paper and are planning to do so again (group B) selected the following as their main reasons: getting the opportunity for professional success and acknowledgement, getting to know an interesting field of science and research experience; this is, of course, besides the thesis preparation, which was picked by everybody as a practical motivational factor. These students have become enthusiastic about the academic/scientific work and they wish to experience success and the thrill achieved by research and recognition. They are the ones who are to be counted within higher level (MSc, Ph.D.) education.

3) Not surprisingly, the motivation of those who do not yet know the SSA system (group C) almost completely coincides with that of the first group: with the additional emphasis on earning extra points for continuing education and developing their presentation skills as well. These students have an open and curious attitude towards their oncoming SSA work, and we, as instructors should keep to the goal of moving as many of them as possible to group B after they have finished their first SSA paper and encouraging them to carry on their professional/academic work.

According to the deductions above, the students of group B can be regarded as the most motivated, talented and valuable in terms of providing new instructors for the faculty; therefore, we analyzed this group and the differences among the reasons of participating in the first and successive SSAs in a more detailed way. 
Sixty-eight students filled out the questionnaire who answered 'yes' to questions 10 and 14; they were the ones who have already participated in an SSA conference and were planning to do so again. These students answered both questions 11 and 16 on the questionnaire. The cause of $1^{\text {st }}$ SSA' bars of Figure 3 indicate students' reasons for participating in their previous (usually their first) conference whilst the cause of $2^{\text {nd }}$ SSA' bars show why they would participate in their next (planned) SSA conference. The post and prior answers of the students effectively point out the changes in their motivation after the first SSA conference.

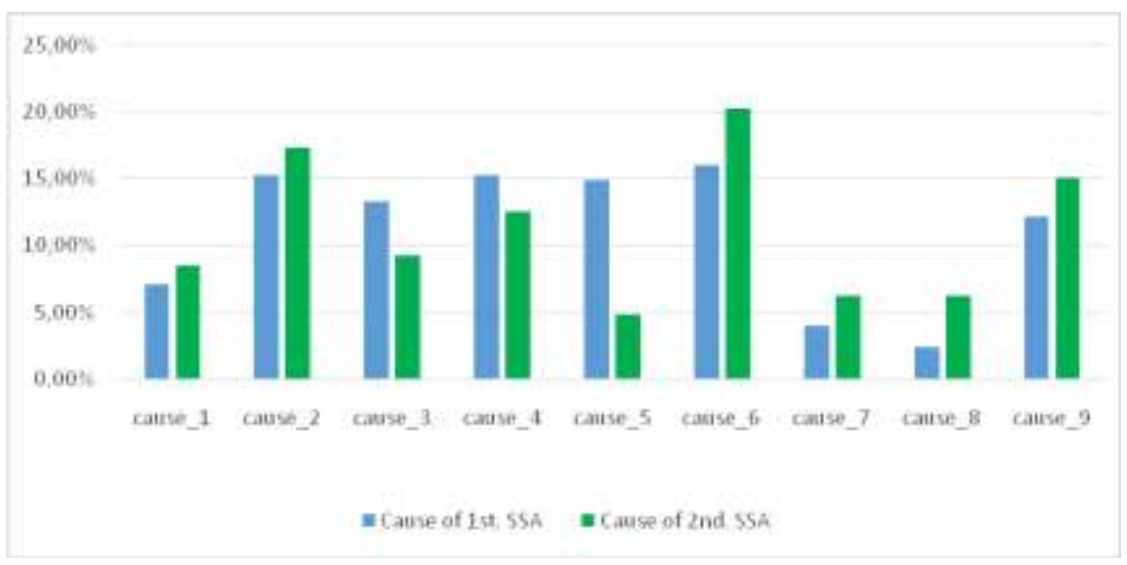

Figure 3

The reasons of students in group B for participating in the SSA for the first and second time

The $\chi 2$ test confirms the presupposition suggested by the chart here as well: the two samples significantly differ from each other $(\chi 2=51.36 ; \mathrm{df}=8 ; p=0)$.

Concerning the second SSA, the students regard the following as

less important ${ }^{3}$ : earning extra points for continuing education (5); development of presentation skills (3); preparation for writing a thesis or degree assignment (4) more important: financial reward $^{4}$ (8); professional success (6); research experience (9); earning extra points for a study grant (7); getting to know an interesting problem (2); presentation of an academic work conducted earlier ${ }^{5}(1)$

The order of the aspects is also in order of importance, moving from the biggest difference towards the smallest one. By analyzing the 68-element even sample (prior and postal condition), we used the McNemar test to show that the following factors changed significantly (at a significance level of 0.05 ):

3 The brackets contain the number of the choice of answer given to question 16 in Table 2

4 The first three places receive a financial contribution at the BME, and corporate and faculty (etc.) special prizes are also awarded.

5 Practically this often means that the student carries on his/her work introduced in the first SSA paper, and develops it further in his/her second SSA. 
The role of the reasons has significantly...

\section{Increased}

Financial reward $(p=0.001)$

Professional success $(p=0.011)$

Research experience $(p=0.041)$

\section{Decreased}

Earn extra points for continuing education $(p=0)$

The data above suggest that the students usually do their second SSA because of research experience and the prospects of professional success, while it is not a negligible factor that the successful papers receive a financial reward. Not being a principal aspect, but due to the current rates of student grants besides the low levels of social financial student contributions, many students warmly welcome the several ten thousand forints won with an SSA paper, which, as our survey suggests, represents a significant motivating factor in terms of their participation for the second time. The fact that earning extra points for continuing education is no longer important for the second SSA indicates that the student does not regard his/her second SSA as a 'compulsory' action after already having done one before. Despite this aspect, the weighted consideration of SSA for MSc and Ph.D. admissions, study programs and study trips abroad could be encouraged if somebody participated several times in SSA during his/her university years.

In regards to different life situations and aims, I investigated the reasons of group B with a division to Bachelor's and Master's degrees as well. (Figure 4) In the group, there are 38 students studying for their Bachelor's and 30 studying for their Master's degree. When analyzing the reasons of Bachelor's and Master's students for the prior and successive SSA, I found that there is no significant difference only among the reasons for participating in the successive SSA $(\chi 2=11.231 ; \mathrm{df}=8$; $p=0.189$ ).

Figure 4 shows that there is a difference among the reasons of the first and successive SSAs, and the reasons of Master's degree students. Certain tendencies are evident. Research experience becomes more and more important as the studies progress. The first Bachelor-level SSA is followed by the second Bachelor-level SSA, and the value is the highest in the case of the second Master's-level SSA. It can be clearly seen that, as the students more seriously engage in their studies and the extracurricular SSA task, research experience, the opportunity for professional success and getting to know an interesting problem become more important.

Nevertheless, when examining each difference from the students' educational level with a McNemar test, the results suggest that the motivational factors mentioned previously are important for the Bachelor's students, but the situation is slightly different for Master's students.

It is an interesting fact that BSc students are especially enthusiastic and they would be happy to get to know interesting fields or would earn extra points for a study grant with their second SSA, while MSc students do not share these characteristics; this may also be traced back to the issue that the education is not practical enough. 


\section{Significant reasons of BSc students}

Earning extra points for continuing education $(\downarrow, p=0.002)$

Earning extra points for a study grant $(\boldsymbol{\uparrow}, p=0.004)$

A financial reward $(\boldsymbol{\uparrow}, p=0.004)$

Getting to know an interesting field (个, $\mathrm{p}=0.008)$

\section{Significant reasons of MSc students}

Earning extra points for continuing education $(\downarrow, p=0.001)$

Research experience $(\boldsymbol{\uparrow}, p=0.039)$

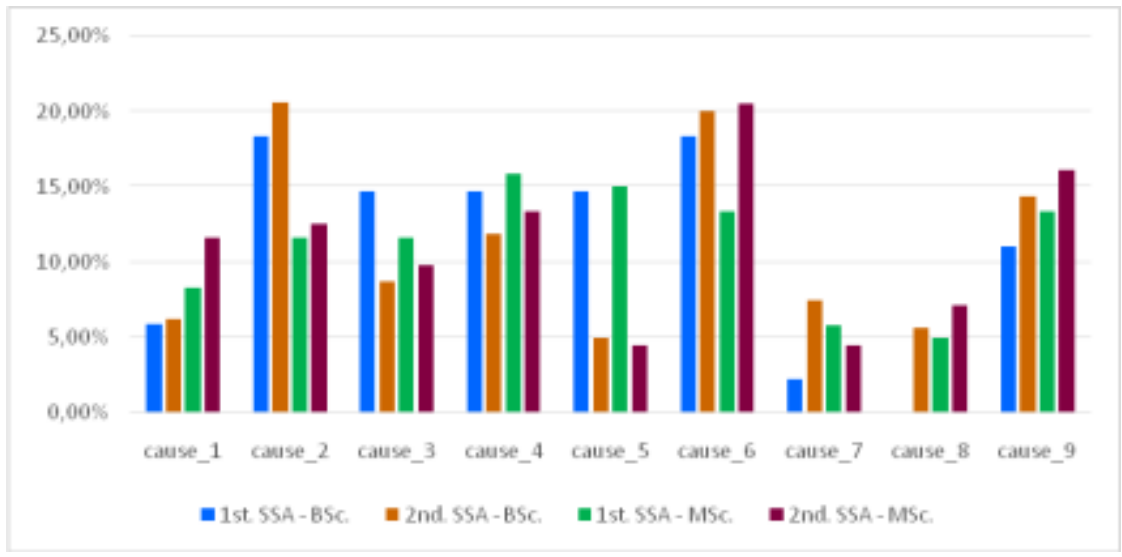

Figure 4

Students belonging to group B, divided into Bachelor and Master categories

When compared with their BSc fellows, MSc students seem more disillusioned in terms of the preparation for the thesis, improvement of presentation skills and earning different extra points. Fortunately, research experience has become the main decisive factor on both educational levels as these students have been 'infected' in a good way, as they caught the 'fever of doing research', and they are willing to prepare their second SSA paper. The poor financial condition of the students is marked by the fact that the financial reward becomes more and more important for them as their studies progress. However, while the BSc students, based on the results above, are quite unlikely to be aware that they can get financial rewards/compensation for achieving good results at SSA, they are not motivated by this factor: Master's degree students know about this benefit as well. (This can be simply explained by the fact that they have spent several years at the university, know how the system works and have more information than their fellow BSc students due to their greater involvement. The majority of the students that were analyzed had attended the BME prior to their MSc studies as well). In the case of the second SSA, financial compensation becomes important for students of both educational levels. 


\subsubsection{The Cross-Table Analysis of Student Characteristics}

In my research, I aimed to better get to know the students joining SSA and participating in the conference. For this, I measured the variables of the questionnaire on a nominal scale and analyzed the correlation between every pair with the help of cross-tables. The significance level of the Pearson value from the $\chi 2$ test helped to deduce whether the two variables were dependent or independent from each other (Table 3 ). If the value is smaller than 0.05 , which is the generally accepted value in such research, then there is a significant relation between them. To analyze the strength of the relations, I chose Cramer's V association method as it is regarded as more reliable than other coefficients and can be used in case of any cross-tables. In the majority of the analysis, Cramer's V equals the $\Phi$ value as I have nominal $2 \times 2$ tables due to the yes/no options of the questionnaire. The value indicating the strength of the relationship can be between 0 and 1, with zero (0) indicating the lack of any correlation, and one (1) representing a strong correlation between the variables.

Table 3

The results of the $\chi^{2}$ analysis of different student groups and characteristics $(\mathrm{df}=1)$

\begin{tabular}{|c|c|c|c|c|c|c|c|c|c|}
\hline & \multicolumn{3}{|c|}{ group A } & \multicolumn{3}{c|}{ groups B+C } & \multicolumn{3}{c|}{ groups A+B+C } \\
\hline Q* & $\chi^{2}$ & $p$ & Cr.V. & $\chi^{2}$ & $P$ & Cr.V. & $\chi^{2}$ & $P$ & Cr.V. \\
\hline 1. & 5.353 & 0.021 & 0.116 & 10.321 & 0.001 & 0.161 & 18.209 & 0 & 0.214 \\
\hline 2. & 1.453 & 0.228 & 0.060 & 6.826 & 0.009 & 0.131 & 0.705 & 0.401 & 0.042 \\
\hline 3. & 6.771 & 0.009 & 0.130 & 4.498 & 0.034 & 0.106 & 3.674 & 0.055 & 0.096 \\
\hline 4. & 52.671 & 0 & 0.363 & 10.416 & 0.001 & 0.161 & 42.864 & 0 & 0.327 \\
\hline 5. & 26.744 & 0 & 0.259 & 8.976 & 0.003 & 0.150 & 16.115 & 0.003 & 0.201 \\
\hline 6. & 31.066 & 0 & 0.279 & 8.691 & 0.003 & 0.147 & 24.940 & 0 & 0.250 \\
\hline 7. & 14.635 & 0 & 0.191 & 10.894 & 0.001 & 0.165 & 13.004 & 0 & 0.180 \\
\hline 8. & 8.391 & 0.004 & 0.145 & 0.092 & 0.762 & 0.015 & 5.525 & 0.019 & 0.118 \\
\hline 9. & 0.178 & 0.673 & 0.021 & 10.025 & 0.002 & 0.158 & 3.421 & 0.064 & 0.092 \\
\hline 10. & 0.956 & 0.328 & 0.049 & 58.369 & 0 & 0.382 & 37.955 & 0 & 0.308 \\
\hline 11. & 0.060 & 0.806 & 0.012 & 26.247 & 0 & 0.256 & 9.089 & 0.003 & 0.151 \\
\hline 12. & 31.378 & 0 & 0.280 & 55.610 & 0 & 0.373 & 46.653 & 0 & 0.342 \\
\hline 13. & 0.108 & 0.743 & 0.016 & 11.702 & 0.001 & 0.171 & 6.404 & 0.011 & 0.127 \\
\hline 14. & 3.085 & 0.079 & 0.088 & 0.058 & 0.810 & 0.012 & 0.292 & 0.589 & 0.027 \\
\hline 15. & 0.560 & 0.454 & 0.037 & 0.050 & 0.822 & 0.011 & 0.098 & 0.755 & 0.016 \\
\hline 16. & 0.061 & 0.970 & 0.012 & 1.381 & 0.501 & 0.059 & 0.773 & 0.679 & 0.044 \\
\hline
\end{tabular}

*Questions in Table 3: 1. Member of a $\mathrm{CAS}^{6} ; 2$. Active athlete; 3. Doing social work; 4. Reading academic books; 5 . Visiting the library; 6 . Getting a student grant; 7. Participated in the NCSS ${ }^{7} ; 8$. Participated in the ESET ${ }^{8}$; 9. Already studied abroad; 10. Planning to do the ESET; 11. Planning to

6 CAS: the "College for Advanced Studies" is a special college for talented students

7 NCSSS: National Competition of Secondary School Studies

$8 \quad$ Participated in a university case study competition (ESET, TIMES, etc.) 
study abroad; 12. Planning an academic career; 13. Education type (BSc/MSc); 14. Living in a dormitory; 15. Sex (male/female); 16. Financial status

By analyzing the voluntarily admitted study results with the non-parametric Mann-Whitney test, I found that the study results of the examined groups were significantly larger than those who were respondents but were not involved at all in the SSA. (Table 4)

This result is not surprising as it is generally the better students who set out to prepare (or plan to prepare) an SSA paper and defend it in a public conference.

Table 4

Grade point average (GPA) of the involved groups

\begin{tabular}{|c|c|c|c|c|c|c|c|c|}
\hline \multicolumn{2}{|c|}{ group A } & \multicolumn{3}{c|}{ groups B+C } & \multicolumn{3}{c|}{ groups A+B+C } \\
\hline $\mathrm{Z}$ & $p$ & $\begin{array}{c}\text { GPA } \\
\text { BSc/MSc }\end{array}$ & $\mathrm{Z}$ & $p$ & $\begin{array}{c}\text { GPA } \\
\text { BSc/MSc }\end{array}$ & $\mathrm{Z}$ & $p$ & $\begin{array}{c}\text { GPA } \\
\text { BSc/MSc }\end{array}$ \\
\hline-8.086 & 0 & $3.45 / 4.05$ & -2.924 & 0.003 & $3.55 / 3.75$ & -6.902 & 0 & $3.37 / 3.83$ \\
\hline
\end{tabular}

Table 5 summarizes the conclusions that were have drawn from Table 3 and Table 4. I grouped the student characteristics from Table 3 and Table 4 into three categories: professional commitment, study results and the students' financial status. (According to the results, leading an active social life (Q2, Q3, Q14.) does not influence the students' participation/intention to participate in SSA.)

Table 5

The grouping of the student characteristics

\begin{tabular}{|l|l|l|}
\hline \multicolumn{1}{|c|}{ Professional commitment } & \multicolumn{1}{c|}{ Study results } & \multicolumn{1}{c|}{ Financial status } \\
\hline Member of a student college & Visiting the library & Getting a student grant \\
\hline Reading academic books & Getting a student grant & Living in a dormitory \\
\hline Visiting the library & Participated in the NCSS & Financial status \\
\hline Participated in the ESET & Studied at a university abroad & \\
\hline Planning to do the ESET & Planning to study abroad & \\
\hline Planning an academic career & GPA & \\
\hline
\end{tabular}

I used bold letters to highlight the factors in which we experienced an at least weak-average correlation based on the data of Table 3 and Table 4.

As we can see Students' financial status is not a very influencing factor. However, characteristics pertaining to professional commitment and university results appear to be significant in the case of students who are engaged in SSA. These students are more hard-working, interested, have better study results and are, by all means, more talented than an average university student is. They all have an interest in their profession and constantly and self-consciously prepare both for general classes (by using the library and reading academic books) and for extracurricular activities (student college, self-conscious preparation for an academic career). Of course, this attitude is reflected by their GPA and the student 
grant related to that. The student grant, however, is not the reason but the consequence of their higher level of interest. Concerning the participation (and planned participation) in case study competitions and studying abroad, I mainly experienced a weak significance in each subgroup depending on each group. On one hand, this refers to the fact that the students are informed about these opportunities only incidentally or from their own inquiry, possibilities or network, in many cases even by chance, and they plan to participate accordingly. On the other hand, the students who have already participated in SSA will not share their capacities and will rather stay away from otherwise less-advertised case studies and other competitions that are regarded as less useful. The 'weak' level of significances fundamentally indicates that improvement would be needed. The Colleges for Advanced Studies, for example, could oblige their members to prepare an SSA paper, while the faculty could increase the number of academic books and conference participations among the prizes, thus, improving the professional interest of the students (which they basically already have). Additionally, we could also award the students doing SSA with extra points for the applications of exchange programs, etc. I did not experience major differences in terms of the education levels. It can be noted, though, that a somewhat stronger (rather average than weak) significance was present concerning CAS membership, the student grant and the NCSSS in the group of Master's students who were planning an SSA. This refers to the fact that Master's students take prior professional preparation somewhat more seriously, and a 'real' SSA paper is created from the 'planned ones' with a bigger proportion in their case than in the case of their more enthusiastic but professionally less experienced Bachelor fellow students.

\section{Conclusions and Further Research Directions}

In the article, I interpreted the process of talent-nurturing in higher education as a key process of education quality management, and we analyzed the SSA movement as a tool for realizing talent-nurturing. The Budapest University of Technology and Economics has great traditions of SSA work. Therefore, a suitable amount of experience and data is available to determine the motivations of the involved students with the help of statistical analytical methods. On one hand, I aimed to reveal what reasons motivate the students to join SSA once or several times, and to see if the students participating in this particular form of talent-nurturing share any common characteristic features.

In this research, it became evident for me, that talent-nurturing is an important element of the services of a quality university: it is a key process. The BME SSA system of our university works well in the basics as a main tool of talentnurturing; however, minor changes and alterations are needed in order to increase efficiency and to reach out to even more students. I showed that students do SSA because of various reasons: their main motivations are to get to know an interesting problem field, earn the opportunity for professional success and acknowledgement, and prepare for a thesis/degree assignment. I found differences 
between the reasons of the first and second SSA; although research experience already becomes an important factor in this case, I have mentioned that the financial reward and the rate of the rewards are equally important. The only bigger difference between Bachelor's and Master's students was that the older, more mature and more experienced Master's degree students prepare more consciously for their professional and/or academic career, and they regard the SSA as a tool for this conscious preparation. I pointed out that students participating in SSA share common characteristics, and these are mainly of professional or academic nature, as I did not find significant corresponding aspects for their community/social life.

After having proved my suppositions with the methods of mathematical statistics and knowing the characteristics, reasons and their correlation, I introduce the following proposals: I suggest that Bachelor's and Master's degree students should be separated, and we should audit and reward them in separate sections in the SSA conference. It would be advisable to prepare and standardize a system about how to consider SSA participation and SSA competition places for student grants, exchange and study trips and Master's and Ph.D. admissions. I deem it justified to consider because students have participated in SSA more than once. I propose that the faculty should adopt an intensive internal marketing activity to promote SSA in which we should raise students' attention about the issues that were previously mentioned. This research did not analyze if students were satisfied with how the SSA system worked, as a process, but I believe that it would be worth addressing this topic. For the future, the Department of Management and Corporate Economics plans to examine if the SSA system (as a fundament of our talent-nurturing system) could be improved in a technical manner by using the methodology toolkit of the Total Quality Management-based quality assurance system of the faculty.

\section{References}

[1] Balogh, L.: The Talent-Nurturing Programme of the University of Debrecen, Educatio, XVIII/1, 2009, pp. 174-187

[2] Bálint, J., Polónyi, I., Siklós, B.: The Quality of Higher Education, Higher Education Research Inst. Bp. 2006, pp. 11-14

[3] Bérces, R.: The Support of Quality-oriented Higher Education with Modern Valuation Methods, PhD dissertation, BME, 2004, pp. 60-72

[4] Bodnár, G.: Talent-Nurturing in Higher Education, In: Kun Á., Takács I. (edited): Teachers' Manual for Talent Nurturing, Typotex Publishing, Bp., 2014, pp. 7-18

[5] Finna H.: Increasing Employment Opportunities and Motivation among Fresh Graduates with Atypical Solutions, In: Topár J. (edited): The Current Issues in Technical Management, Müszaki Kiadó, Bp., 2012, pp. 243-259 
[6] Gholami, M. H. et al: Investigating the Influence of Knowledge Management Practices on Organizational Performance: an Empirical Study, Acta Polytechnica Hungarica, Vol. 10, No. 2, 2013, pp. 205-216

[7] Heidrich, B.: The Student-based Approach of Service Quality in Higher Education, Hungarian Quality, Vol. 19, No. 12, 2010, pp. 6-22

[8] Heller, K. A.: Identification: an Integral Part of Gifted Education, In: Ziegler A. et al.: Gifted Education as a Lifelong Challenge, LIT Verlag, Berlin-Zürich-Münster, 2012, pp. 81-95

[9] Jäckel, K.: Frontline Audit in Higher Education: Exploring Conflicts at Higher Education Institutions, Ph.D dissertation, Szent. István University, 2010, pp. 36-42

[10] Kövesi, J., Tóth, Zs. E., Jónás, T.: How Much is Intellectual Capital Worth for the Organization?, Acta Oeconomica, Vol. 62, No. 1, 2012, pp. 65-91

[11] Kövesi, J., Tóth, Zs. E.: Supporting Efforts to Measure Intellectual Capital through the EFQM Model, Periodica Polytechnica Social and Management Sciences, Vol. 16, No. 1, 2008, pp. 3-12

[12] Kun, Á., Takács, I.: Instructors' Manual for Talent-Nurturing, Typotex Ltd., Budapest, 2014, p. 106

[13] Nftv: The CCIV. Law about National Higher Education from 2011, Magyar Közlöny (118), Bp., 2014, pp. 12862-12869

[14] Ritzer, G.: The McDonaldization of Society - Revised New Century Edition, Pine Forge Press, Thousand Oaks, CA, 2004, p. 312

[15] Subotnik, R. F., Stone, K. M., Steiner, C.: Lost Generation of Elite Talent in Science, Journal of Advanced Academics, Vol. 13, No. 1, 2001, pp. 3343

[16] Sundbo, J.: The Service Economy: Standardization or Customisation?, The Service Industries Journal, Vol. 22, No. 4, 2002, pp. 93-116

[17] Tóth, P.: The Role of Individual Differences in Learning, Acta Polytechnica Hungarica, Vol. 11, No. 4, 2014, pp.183-197

[18] Tóth Zs E, Jónás T.: Enhancing Student Satisfaction Based on Course Evaluations at the Budapest University of Technology and Economics, Acta Polytechnica Hungarica, Vol. 11, No. 6, 2014, pp. 95-112

[19] Weinert, F. E., Helmke, A.: Der gute Lehrer: Person, Funktion oder Fiktion?, In: A. Leschinsky (edited): Die Institutionalisierung von Lehren und Lernen. Beiträge zu einer Theorie der Schule, Betz, Weinheim, 1996, pp. 223-233 